\title{
Sobre la impertinencia de las políticas austericidas: algunos efectos y reflexiones desde el ámbito de la universidad
}

On the Impertinence of Austericide Policies: Some Effects and Reflections From the University Space

Delia Langa-Rosado'

\section{Resumen}

En esta aportación se describirán brevemente cuáles fueron las principales transformaciones en las condiciones de acceso y permanencia en los estudios universitarios que tuvieron lugar a partir de las reformas post- 2012 en un escenario de austeridad en el gasto público. Se parte del más reciente trabajo de investigación de la autora en torno a esta temática y se concluye con el carácter de reajuste clasista a que dichos cambios dieron lugar. En un apartado final se esbozan algunos argumentos que, en el contexto actual de crisis sanitaria y social, refuerzan la valoración de la inoportunidad de ese giro inequitativo en la política universitaria.

\section{Palabras clave}

Educación universitaria, estudiantes, desigualdad educativa, clases sociales, política universitaria.

\section{Abstract}

In this paper we will describe briefly the main changes in the access and permanence conditions in the university after post-2012 reforms, in a scene of austerity in public spending. Based on Langa-Rosado's recent research it is concluded that last changes have provoked an increase of social class inequalities between students. In a final section we outline some arguments that reinforce the inopportuneness of this inequal turn in university policies, taking account the present context of sanitary and social crisis.

\section{Keywords}

University education, students, educational inequality, social clases, university policies.

\section{Cómo citar/Citation}

Langa-Rosado, Delia (2020). Sobre la impertinencia de las políticas austericidas: algunos efectos y reflexiones desde el ámbito de la universidad. Revista de Sociología de la Educación-RASE, 13 (2) Especial, COVID-19, 164-173. http://dx.doi.org/10.7203/RASE.13.2.17131. 
El dinero no puede comprar la vacuna que no tenemos, no puede comprar las máscaras protectoras que no se han producido, no puede comprar los departamentos de cuidados intensivos que han sido destruidos por la reforma neoliberal del sistema de salud de Europa. No, el dinero no puede comprar lo que no existe. Solo el conocimiento, solo el trabajo inteligente puede comprar lo que no existe.

Asi el dinero es impotente ahora. Solo la solidaridad social y la inteligencia científica están vivas, pueden volverse políticamente poderosas. (Bifo Berardi, 2020).

\section{Introducción. Repensar la propia investigación en tiempos de COVID-19}

No resulta fácil reflexionar, de un modo mínimamente oportuno, en la inmediatez de este período de convulsión sanitaria, económica, social e incluso civilizatoria, al decir de algunos. Un período que nos tiene a todos conmocionados, expectantes y confrontados con un altísimo grado de incertidumbre. Se me ocurre, dada la excepcionalidad de la situación, abordar mi aportación de un modo atravesado por lo personal en mayor medida de lo que solemos hacer en los medios académicos. Me voy a permitir, pues, comenzar a hablar del tema que me ocupará aquí esbozando algunos retazos biográficos que, no obstante, explican algo de mi modesta trayectoria académica y, sobre todo, del interés por el tema de las desigualdades educativas que hasta ahora la ha recorrido.

Mis orígenes sociales me situarían manifiestamente en una clase obrera no cualificada: padre peón básico en una agroindustria aceitunera y madre costurera. Familia de cuatro hijos, nacidos entre los 70 y principios de los 80 , de los cuales todos -tres mujeres y un varón- accedieron y completaron exitosamente estudios universitarios. Mi trayectoria podría ejemplificar, pues, la de una baby boomer beneficiaria de los procesos de expansión universitaria de los 80 y los 90 del siglo pasado que experimentaron todas las clases sociales, aunque en ningún caso en la misma medida. A los de mi generación -J.A.S.P. (joven, aunque sobradamente preparada) - en efecto, nos caracterizó una muy buena voluntad educativa y unas expectativas más bien optimistas sobre las posibilidades de funcionamiento del sistema escolar como ascensor social, al menos en sus años más jóvenes. En efecto, con diferencias entre clases, que nunca dejaron de ser claramente perceptibles y aún más entre los varones, nos tocaron juventudes de gran esfuerzo educativo personal, y también familiar. Fuimos estudiantes de primera generación muy conscientes, por ello, del enorme sacrificio que realizaban nuestros padres al prolongar en el tiempo la dependencia de sus recursos en aras de continuar nuestras apuestas educativas. Aunque gozamos de becas, éstas no siempre fueron lo suficientemente cuantiosas e incondicionales, y el apoyo de las familias, que además dejaban temporalmente en suspenso la ansiada colocación de los hijos, nunca dejó de sentirse como condición sine qua non para continuar con las apuestas universitarias en aquellos casos aun excepcionalmente exitosos como el mío, o el de mis hermanos, que habíamos sorteado dificultades varias y logrado alcanzar los peldaños superiores del sistema escolar. Por qué me detengo en estos detalles. Creo que precisamente esta experiencia personal tuvo mucho que ver en la inquietud que me llevó, allá por los últimos años 90, a realizar mi tesis doctoral sobre las diferencias entre clases sociales en los modos de abordar, de decidir y de vivir las experiencias universitarias. Una de mis principales conclusiones fue justamente destacar como elemento característico de los estudiantes de clases populares un muy expresivo sentimiento de deuda ${ }^{2}$ que recorría los discursos de los estudiantes y tamizaba muchas de las decisiones y conductas de

2 Mi tesis fue cualitativa, con entrevistas en profundidad. 
las trayectorias estudiantiles (si se estudiaba había que responder, ser «responsables» ante la familia y la sociedad, pues acceder a la universidad no se entendía en ningún caso como un derecho incuestionable). Los tintes incluso a veces moralizantes de estos discursos lo que mostraban -concluía en mi análisis- es que la expansión educativa de la democracia en nuestro país se hizo a expensas de un gasto educativo creciente, sí, pero en ningún caso similar al de los países europeos de nuestro entorno ${ }^{3}$; por lo que al menos igualmente necesario para esta expansión resultó el enorme esfuerzo/sacrificio de las familias, sobre todo las de clases populares, que entendieron que apostar por la educación de sus hijos era el mejor legado que podían transmitirles.

¿Dio lugar este proceso, del que fue mi generación una de las pioneras, a una verdadera democratización de la universidad? Más desde luego en el imaginario social que en lo que tiene que ver con las posibilidades de las distintas clases de llegar exitosamente a la educación terciaria. Si atendemos a los datos de la siguiente tabla, que recoge la evolución de las tasas de escolarización por clase social a lo largo de los años de nuestra democracia, hasta el 2103, vemos cómo para los hijos de las familias de clase trabajadora las probabilidades de acceder a estudios universitarios, aun habiendo crecido desde los 70, seguían siendo minoritarias. Apreciamos cómo las probabilidades están en torno al 20-25\% en 2013, aunque se partía de en torno a solo un 15\% en los 70; para las clases altas, que tenían en los 70 niveles cercanos al $60 \%$, esta cifra sube al 75\%. En cualquier caso, a pesar del aumento de probabilidades para las clases bajas, en 2013 seguíamos teniendo un escenario en el que lo que para unos era lo normal, ir a la universidad (tres de cada cuatro), para otros, los de familias obreras, era justo lo contrario (solo iba uno de cada cuatro).

Tabla I. Estudian o han terminado universidad por clase social

\begin{tabular}{|c|c|c|c|c|c|c|c|c|}
\hline & PROFESIONALES & DIRECTIVOS & ADM. COM & AUTÓNOMOS & OBREROS & $\begin{array}{c}\text { AGRARIOS } \\
\text { (CUENTA } \\
\text { PROPIA) }\end{array}$ & $\begin{array}{c}\text { AGRARIOS } \\
\text { (CUENTA AJENA) }\end{array}$ & TOTAL \\
\hline $\begin{array}{l}\text { EPA 1990, } \\
\text { NAC 69-70 }\end{array}$ & $59,1 \%$ & $67,9 \%$ & $37,9 \%$ & $25,3 \%$ & $14,9 \%$ & $17,9 \%$ & $5,7 \%$ & $23,9 \%$ \\
\hline $\begin{array}{l}\text { EPA 2000, } \\
\text { NAC 79-80 } \\
\text { COH.16 }\end{array}$ & $59,5 \%$ & $75,2 \%$ & $48,4 \%$ & $31,9 \%$ & $20,4 \%$ & $29,2 \%$ & $18,6 \%$ & $32,7 \%$ \\
\hline $\begin{array}{l}\text { EPA 2004, } \\
\text { NAC 83-84 }\end{array}$ & $62,3 \%$ & $69,7 \%$ & $43,0 \%$ & $31,3 \%$ & $20,9 \%$ & $36,4 \%$ & $8,6 \%$ & $33,1 \%$ \\
\hline $\begin{array}{l}\text { EPA 2007, } \\
\text { NAC 86-87 }\end{array}$ & $62,3 \%$ & $60,9 \%$ & $42,1 \%$ & $34,2 \%$ & $19,8 \%$ & $41,1 \%$ & $13,8 \%$ & $33,5 \%$ \\
\hline $\begin{array}{l}\text { EPA 2013, } \\
\text { NAC 92-93 }\end{array}$ & $73,2 \%$ & $76,4 \%$ & $44,6 \%$ & $44,5 \%$ & $24,3 \%$ & $26,6 \%$ & $19,7 \%$ & $38,8 \%$ \\
\hline
\end{tabular}

Fuente: Informe Situación Social de España 2015, CIS.

Todo esto por qué lo cuento. Porque es justo lo que había antes de una serie de medidas de política universitaria, aún recientes, que se adoptaron a partir de 2012 y 2013 con la justificación de la necesidad de austeridad presupuestaria con la que las autoridades políticas nacionales y europeas respondieron a la anterior crisis socioeconómica. Dado mi interés por la persistente desigual estructura de oportunidades

3 En España las tasas universitarias no han sido nunca de las más baratas de la Unión Europea, ni siquiera antes de la reforma 2012 y la cobertura de becas también ha sido uno de las más escasas (un 25\% situándonos en el puesto 23 de los 39 considerados en un estudio comparativo de CCOO (2016) con datos Eurydice). 
educativas, empecé a seguir de cerca tales cambios institucionales con el foco especialmente puesto en cómo podían reforzar los mecanismos de inequidad que nuestras nunca suficientemente holgadas políticas públicas habían logrado eliminar en tiempos de bonanza.

Paso, pues, ahora, a describir brevemente cuáles fueron las principales transformaciones en las condiciones de acceso y permanencia en los estudios universitarios que tuvieron lugar a partir de 2012, y algunos de los efectos que estos cambios han ocasionado. Obviamente, y dado que esto ya se ha publicado en otros medios, a lo que quiero finalmente llegar en esta contribución es a una reflexión sobre la inoportunidad de dicho giro en la política universitaria, y como algunas evidencias que el actual escenario de parón sistémico nos está mostrando, refuerzan el juicio de dicha inoportunidad, incluso impertinencia, al sentir, muy personal -que hoy me lo estoy permitiendo- de la situación que se nos ha venido encima.

\section{Reajuste clasista en la universidad española al frío de las políticas de austeridad ${ }^{4}$ de la anterior crisis}

Tanto en nuestro país como en otros muchos de la OCDE desde los 90 veníamos siguiendo la tendencia a incrementar gradualmente los precios de las matrículas universitarias. No obstante, en 2012, al frío de los tijeretazos educativos y en concreto de la aplicación del llamado decreto Wert, experimentamos una muy abrupta y memorable subida. Aunque con importantes diferencias territoriales, las tasas se incrementaron en torno a un 32\% en los grados y un 75\% en los másteres, ya de por sí bastante más caros desde el proceso de Bolonia. Otro giro sustantivo del Real Decreto ley 14/2012 es que introdujo, a modo de tasas de demérito, el criterio por el que se hacen depender los precios del logro académico (se empiezan a incrementar progresivamente a partir de la segunda matrícula). Tanto esta última medida como los precios más elevados de los másteres configuran rasgos muy particulares de nuestro sistema universitario en relación con Europa.

Otra muestra de la excepcionalidad de nuestro sistema en el contexto de la mayoría de los países europeos tras la crisis de 2008, es que, lejos de lo que cabría esperar tras la reforma de las tasas, desde 2013 se ha ido llevando a cabo a través de distintos decretos una mutación sustantiva en el sistema de becas. Uno de los principales cambios consiste en que se hace depender en mayor medida la obtención de las ayudas así como la cantidad de éstas de los logros académicos; por otro lado, el sistema pasa a adquirir un claro carácter competitivo: en la parte compensatoria de las becas se introducen condiciones variables que dependerán de los resultados del solicitante y de los demás solicitantes así como del presupuesto anualmente destinado. El proceso de asignación de las ayudas, al priorizar que el gasto público quede restringido a lo inicialmente presupuestado (en todos estos años ha caído un 13,5\%) se hace no solo competitivo, sino en cualquier caso más complejo e incierto para el becario. A resultas de todas estas transformaciones, en un escenario de crisis donde los becarios no han dejado de crecer, lo que sí ha descendido notablemente es la cuantía de las becas, en torno a un $20 \%$, o casi un $50 \%$ si hablamos de las familias con las rentas más bajas (Hernández y Pérez, 2018).

Hemos asistido, pues, a un importante giro en el sistema de financiación de la universidad pública, que apuntala doblemente la tendencia a que aumente la parte del gasto que recae en los estudiantes y sus

\footnotetext{
4 Para este resumen de los principales cambios institucionales, en línea con la intención de aportar reflexiones orientadas a la acción en un contexto como el actual, voy a valerme de un artículo divulgativo (http://agendapublica.elpais.com/reajuste-clasista-en-la-universidad-espanola/) que publiqué en Agenda Pública. El País el día 3 de diciembre de 2019. Lo reproduciré casi literalmente introduciendo solo aquellos elementos novedosos necesarios para hilar el contenido de este documento.
} 
familias; por otro lado, y no menos importante, las nuevas medidas han regulado una mayor dependencia del coste de estudiar del rendimiento académico del alumno.

¿Qué sentido tienen estas dos reformas consecutivas y aparentemente contradictorias? ¿Mejorar la eficiencia y promover la cultura del esfuerzo entre nuestros estudiantes, hacer que la Universidad no sea tan fácil y barata en nuestro país, como justificaban en su día los responsables de estas políticas?

Sabemos, en efecto, que uno de los puntos flacos del funcionamiento de nuestras instituciones universitarias tiene que ver con el alto porcentaje de alumnos que abandonan sus estudios, en torno a un tercio; así como con los bajos porcentajes de idoneidad y graduación de los estudiantes: algo más de la mitad no logra alcanzar su titulación correspondiente incluso en un curso más de lo previsto (Hernández y Pérez, op. cit). No podemos olvidar, no obstante, que otro de los déficits estructurales de la universidad española es la equidad tanto en el acceso como en el progreso de la carrera académica (Ariño et al., 2019). Como comentábamos en el apartado anterior, para amplios sectores de las clases populares la Universidad no ha sido ni siquiera antes de las reformas una apuesta muy accesible, o al menos no tanto como para sus compañeros de orígenes sociales más elevados. ¿Es posible pensar que la desigualdad no se va a ver multiplicada por las reformas de las tasas y las becas?

Aumentar el costo privado de los estudios por la subida de las tasas prácticamente a la vez que se transforman las condiciones de consecución y mantenimiento de las becas, qué duda cabe que al grupo al que más va a afectar es el de aquellos estudiantes de orígenes populares necesitados de ayudas para poder realizar su carrera. Aplicar medidas «eficientistas» que a la postre van a repercutir especialmente en éstos no tiene mucho sentido, pues ya se trataba, como decíamos más arriba, de un colectivo especialmente «conseguidon» y responsable: el comportamiento académico de los becarios es más eficiente que el del resto de los estudiantes (Río-Ruiz, Jiménez-Rodrigo y Caro-Cabrera, 2015); se presentan y aprueban más las asignaturas matriculadas, tienen mayores tasas de rendimiento, éxito y evaluación (Hernández y Pérez, 2017). Muestran, en definitiva, un estilo académico más eficiente y comprometido. Por otra parte, sabemos también que el comportamiento de los jóvenes de clases bajas es más autoexigente a la hora de venir a la Universidad: sus expectativas dependen más de los logros conseguidos en etapas anteriores y deciden no solo venir a la universidad o no dependiendo de eso, sino también el tipo de titulación elegida tiene muy en cuenta las posibilidades de lograrlo (Torrents, 2015). Son estudiantes más cautos, menos arriesgados en sus decisiones, al menos más dependientes de los logros académicos, no solo al inicio de sus carreras, sino también a lo largo de éstas. De ahí viene precisamente su mayor tendencia al abandono o a compatibilizar estudios y trabajo en caso de que sus trayectorias sufran algún tipo de «traspiés académico».

Precisamente uno de los principales efectos de las últimas reformas se ha concretado en un endurecimiento de las condiciones que precipitarían estos «fracasos», estos «traspiés» en las trayectorias de este tipo de estudiantes. De hecho sabemos que entre aquellos con carreras «disruptivas» por la pérdida de becas y el pago de matrículas progresivamente más caras, se están implementando estrategias de abandono, suspensión temporal y/o compatibilización de la carrera con algún «trabajillo» (Ariño et al., 2019) lo que a la postre repercute en procesos de demora en la consecución del grado. En el informe de la CRUE del curso 2016-17 se advierte en este sentido de la importante brecha entre las tasas de graduación de las universidades públicas y privadas (16 puntos a favor de estas últimas). En fin, parece que aumentar el condicionamiento a resultados de los costes que implica la opción universitaria no hace sino aumentar las presiones, contradicciones y crear nuevas precariedades a los estudiantes de orígenes populares. Difícil- 
mente podemos imaginar que esto ayude a una más solvente implementación del rol académico y desde luego parece comprometer en uno u otro grado la equidad del sistema.

¿Se está haciendo la universidad menos atractiva para este tipo de jóvenes por los nuevos obstáculos, precariedades e incertidumbres? Aunque es cierto que estas políticas educativas han visto sus efectos en la desigualdad menguados por el aumento del paro juvenil que ha hecho más atractiva la opción de estudiar (Carabaña, 2018; Martínez García, 2019), hay, no obstante, datos que muestran un cambio de tendencia. Apreciamos, por ejemplo, que desde 2012 se viene registrando una caída en el acceso que se concentra en los alumnos de grado de las universidades públicas, pero no en los másteres, y aún menos en los másteres de las privadas. En el caso de las enseñanzas de ciclo y grado, la demanda se ha reducido globalmente en el período post-reformas un 5,2\%. Pero, mientras en las universidades públicas la disminución ha sido del 8,7\%, en las universidades privadas experimentan un crecimiento del 24,1\% (Hernández y Pérez, 2018). De otro lado, y mirando tipos de estudiantes por clase social, aunque aún no hay muchos datos a nivel nacional, se ha identificado (Herrera, 2019) una caída de entre 4,5 y 7 puntos en la representación en el porcentaje que suponen los estudiantes de más bajo nivel socioeconómico entre el curso 2011 y el 2015-16. Igualmente, referido a las universidades catalanas, existen evidencias de que son los estudiantes menos tradicionales los que más están disminuyendo su acceso (Troiano y Torrents, 2018). Lógico, son los que tienen que asumir más riesgos: perder la beca, o tener becas escasas y de incierta cuantía, y asumir la posibilidad de matrículas el doble de caras o más, puede convertirse en un calvario para determinado tipo de joven: una «carrera de obstáculos», al decir de un estudiante hijo de jornalero en una reciente investigación cualitativa (Langa-Rosado, 2018).

Para ir concluyendo, sobre el sentido de las reformas: el giro hacia un sistema más competitivo y basado en la eficiencia parece tener una débil justificación cuando afecta especialmente a quienes no tenían problemas en dar cuenta de sus resultados, y en cualquier caso ocasiona serias contradicciones con lo que debería ser una apuesta por promover una universidad más inclusiva. Emprender y/o continuar estudiando en la universidad está hoy más sujeto a la solvencia económica o a la sobredemostración de talento, en ausencia de la anterior. Por tanto, no es nada desproporcionado hablar de un proceso de reajuste clasista, de un endurecimiento de las condiciones de cierre social (Aja, 2016) que tiene, además, un doble tipo de concreciones adicionales. Por un lado, el aumento del costo privado de los estudios genera una considerable ventaja competitiva para las universidades privadas ${ }^{5}$, que curiosamente como acabamos de señalar, son las únicas entre las que está creciendo, incluso holgadamente, su alumnado. De otro lado, además, el condicionamiento del derecho de estudiar al logro o al origen familiar supone un inequívoco envite en el sentido de debilitar la educación universitaria como derecho ciudadano. Parémonos a pensar ahora si es ésta la senda por la que deberíamos/querríamos seguir para salir y/o no profundizar en la nueva crisis a la que la actual situación de emergencia nos está abocando inexorablemente.

\section{Sobre la inoportunidad de las reformas, al hilo de algunas señales del presente y emergente escenario}

Desde luego la primera y más contundente razón de valoración negativa de las reformas que acabo de describir, ya lo he ido señalando, es precisamente el carácter y los efectos de cierre escolar clasista que es-

\footnotetext{
5 No hay que perder de vista que esto se enmarca en un proceso de ascenso de la universidad privada, que desde 1997 a la actualidad no ha parado de crecer, de modo que se ha pasado de 13 a 35 universidades privadas (frente a 50 públicas), estando matriculados en ella en la actualidad el 16,4\% del total de estudiantes, subiendo este porcentaje al 41\% si hablamos de enseñanzas de máster (Hernández y Pérez, 2018).
} 
tán produciendo. Poner más trabas a quienes tienen más desventajas socioeconómicas supone desvirtuar radicalmente el sentido equitativo que se entiende debe presidir las políticas educativas en una sociedad democrática. Si ya quienes venían de orígenes humildes habían padecido múltiples mecanismos de sobreselección que daban cuenta de su menor presencia en los estudios universitarios, tras la reformas de 2012 han pasado a tenerlo peor. Y no hay que ser muy avispado para prever que el aumento de la desigualdad que experimentamos tras la crisis de 2008 va a verse replicado (y lloverá sobre mojado) cuando comiencen a notarse los efectos del incremento del desempleo y la caída en los niveles de renta de muchos sectores populares que el actual escenario viene ya anunciando. Si las políticas educativas no cambian radicalmente de rumbo, es obvio que tendremos una educación universitaria más alejada del horizonte de posibilidades para amplios sectores a los que la universidad se les representará sencillamente como «cosa de otros».

En una sociedad de capitalismo cognitivo ${ }^{6}$, ¿'es este el modelo educativo que más nos interesa, un modelo en el que el acceso a los más altos niveles formativos esté vetado socialmente? Reflexionemos en torno a esta pregunta mirando algunos honrosos ejemplos de tipos sociales que se han dedicado desde un primer momento a solucionar problemas. En un contexto de evidente imprevisión en cuanto a dotación de insumos y servicios sanitarios, ¿no ha sido realmente encomiable el tipo de experiencias como la de las múltiples comunidades makers que se han puesto a producir digitalmente cosas materiales imprescindibles como las viseras de protección para el personal sanitario? O incluso, con mayor nivel de sofisticación tecnológica, los respiradores creados en este contexto de urgencia por la colaboración en equipos de médicos e ingenieros como el de «Málaga Respira», por poner un ejemplo. Quizá esto apunta a, parafraseando a dos de los protagonistas de este tipo de nuevos fenómenos ${ }^{7}$,

\begin{abstract}
«que tendría que ser un modelo de producción y uso del conocimiento sobre el que tendríamos que reflexionar y pensar mucho más; no ya los aficionados y más o menos frikis, sino las instituciones. Valores como los de la autonomía tecnológica, la producción local, la sostenibilidad, el conocimiento distribuido, la convivencialidad, o la resiliencia (como escribe Cesáreo González en la fuente citada) nos parece que son de gran interés. Y aunque evidentemente, en esta ocasión, el tema de las viseras es bastante limitado, si que sería relevante tratar de pensar a partir de aqui en modelos productivos de mayor arraigo local, más sostenibles y que hagan al país menos críticamente dependientes de las supply chains globales». (Pérez de Lama y Sánchez-Laulhé, 2020).
\end{abstract}

Son muchos los que están indicando, en todo caso, que esta crisis pandémica puede ser una ocasión para repensar el tipo de modelo socioeconómico que queremos ¿reconstruir? Desde las evidencias múltiples del colapso ecológico que parecía no queríamos constatar antes de todo esto, a, bajando más al tema que nos ocupa, la endeblez de un tejido productivo, poco adaptado a una sociedad en que el mayor valor lo aporta el conocimiento, y que derrocha a una juventud subempleada o emigrada, todo parece hacernos cuestionar: ¿No es quizá momento, dada además la buena voluntad educativa demostrada por las familias españolas $^{8}$ de dar un giro radical y apostar por otro tipo de modelo productivo, por el fortalecimiento de la producción local, también material, donde cobren mayor centralidad el saber y el ingenio y todo aquello

6 Sobre los futuros escenarios de evolución del capitalismo también se ha escrito mucho, y muy interesante, en estos días. Aunque mi aportación en este caso no dejar de estar muy apegada a realidades empíricas a veces de un campo de observación muy acotado, nada me gustaría más que ayudar, si quiera modestamente, en este sentido-deseo de imaginar otro tipo de mundo posible.

7 Que por cierto recuerdan en este mismo artículo la reivindicación a las autoridades municipales, en este caso de Sevilla, de crear una red de makers spaces en todos los centros educativos.

8 Que incluso tras la crisis del 2008 han seguido apostando por más educación, cada una según sus posibilidades, y desde luego con desiguales niveles de sacrificio. 
que incorpore valor añadido? Obviamente no hablo de valor mercantil, de aquel orientado a incrementar ganancias a unos cada vez más pocos y poderosos, hablo, como nos propone Bifo Berardi (op. cit.), de rescatar el valor de uso de las cosas frente a la abstracción de la acumulación capitalista, el valor para los cuidados y para la vida.

$\mathrm{Si}$, en efecto, las actuales apremiantes circunstancias están poniendo muy a las claras, por ejemplo, la necesidad de un sistema público universal sanitario robusto y con suficientes recursos, desde luego otro tanto está sucediendo con la valoración social y la confianza depositada en la ciencia. De nuevo, parece que la apuesta pasa por más educación. ¿Es solo apostar por más universidad? No solo -no quisiera idealizar-, y desde luego en la propia institución universitaria, con sus saberes tan traspasados por múltiples jerarquías en su génesis y difusión, tendríamos mucho que aprender de otras formas más distribuidas de producción y circulación del conocimiento; pero, en todo caso, un sistema universitario público, sólido y abierto, parece que ayudaría mucho más que otro tipo de apuestas y concepciones más clasistas de la educación.

Por otro lado, si los que se han arremangado sin pensarlo mucho y han resuelto problemas estos días son los que quizá puedan servirnos de modelo/guía de los que aprender para recomponer nuestras sociedades, igual podríamos reflexionar sobre los tipos opuestos. Aquellos que en vez de resolver se han dedicado a inventar y difundir problemas, aquellos que han mostrado precisamente, a veces con sus insensatas declaraciones (no hace falta «parapetarse en la ciencia»), una adicional manifestación de esta crisis. Me refiero al profundo abismo que se ha revelado estas semanas entre una clase política poco dada a dar cuentas y atrapada muchas veces en bucle de tácticas partidistas ${ }^{9}$, y la gente común. La gente a la que se le ha querido calificar de héroes, pero a la que yo ahora prefiero pensar en términos de ciudadanía, gente «cualquiera» que ha dado claras muestras de responsabilidad y civismo, tanto respetando y desbordando en muchos casos solidariamente las medidas de confinamiento, como al atender sus responsabilidades laborales asumiendo con ello distintos niveles de precariedad y riesgo para sus vidas. ¿No nos está quizá mostrando este escenario también un serio cuestionamiento de los engranajes institucionales que soportan la democracia? ¿Y no es, al mismo tiempo, algo que emerge ahora particularmente, como una especie de renovado sentido común, la idea de que sólo entre todos, con más mecanismos colaborativos y de participación, lograremos salir de ésta? Frente a la lógica de los intereses de un mercado que se ha revelado bastante ciego a lo que sostiene la vida y por ello manifiestamente incompetente, y de unos estados con menos autonomía política de la que desearíamos, la lógica de la cooperación; la nueva gramática política de lo común (Laval y Dardot, 2015). Aquella que se puso de manifiesto en las diversas oleadas de las primaveras populares, en los movimientos quincemayistas en nuestro país, como respuesta a la crisis del 2008, y que quizá debería reeditarse en ésta, con ciertas lecciones aprendidas: otro giro de radicalización de la democracia, más participación de los cualquiera, más vigilancia ciudadana del estado y sus instituciones. Para lo cual de nuevo, y voy acabando, se me ocurre, entre otras muchas cosas, reforzar la educación, como derecho y como instrumento emancipador. Más educación, más aspiraciones, y aún más expectativas educativas, más posibilidades reales de llegar, incluso, a la universidad. También, y especialmente, para las hijas de las cajeras de supermercado, de las limpiadoras, de las cuidadoras...

$\overline{9}$ No quisiera generalizar, y desde luego que hay excepciones, pero, me pregunto: ¿no nos ha dado a más de una la sensación en no pocas de las declaraciones de nuestros políticos en estos días de que no sabíamos muy bien si lo que hacían era jugar a ver si los hechos posteriores les daban la razón y así ganaban en una presunta y delirante partida electoral? 


\section{Referencias bibliográficas}

Aja, Jaime (2016): “Clase, precariedad laboral y crisis de régimen”. Desde abajo, 5, 49-56.

Ariño, Antonio; Martínez, Miquel; Llopis, Ramón; Pons, Ernest y Anna Prades (2019). Via Universitària: Accés, condicions d'aprenentatge, expectatives i retorns dels estudis universitaris (2017-2019). Valencia: Xarxa Vives.

Berardi, Bifo (2020). "Más allá del colapso: tres meditaciones sobre las condiciones resultantes posibles". En Calderón 094. Un blog de crítica cultural escrito por Calderón, M. (en línea) https://calderon094. wordpress.com/2020/04/01/traduccion-mas-alla-del-colapso-tres-meditaciones-sobre-las-condiciones-resultantes-posibles-bifo-berardi-2020/?fbclid=IwAR1Bz2tAP1379yS5kh5FS56lwYsOYS9FEVZCLfXFpyZ19LAhld-kErfXLmM.

Carabaña, Julio (2018): "Los efectos de la crisis sobre el sistema escolar". Revista Española de Sociología, 27 (1), 109-112. DOI: https://doi.org/10.22325/fes/res.2018.6.

Hernández, J. y Pérez, José Antonio (2017). La Universidad española en cifras, 2015/2016. CRUE: Universidades españolas.

Hernández, J. y Pérez, José Antonio (2018). La Universidad española en cifras, 2016/2017. CRUE Universidades españolas.

Herrera Cuesta, Damián (2019): “¿Quién estudia en la universidad? La dimensión social de la universidad española en la segunda década del siglo xxi”. Revista de Sociología de la Educación, (RASE), 12(1), 7-23. DOI: http://dx.doi.org/10.7203/RASE.12.1.13177.

Langa Rosado, Delia (2018): "La apuesta universitaria en los jóvenes de clases populares. Entre la promoción social y la falta de horizonte". Revista Española de Sociología, 27 (1), 137-145. DOI: http://dx.doi. org/10.22325/fes/res.2018.9.

Laval, Christian y Dardot, Pierre (2015). Común. Ensayo sobre la revolución en el siglo XXI. Barcelona: Gedisa.

Martínez García, José Saturnino (2019): “La educación y la desigualdad de oportunidades educativas en tiempos de crisis económica". En VIII Informe Foessa, documento de trabajo 3.9.

Pérez de Lama, José y Sánchez-Laulhé, José (2020). “Makers y plataformas de enseñanza online en la España del coronavirus: dos modelos 'tecnopolíticos' diferentes". Arquitectura contable. Blog feminista, ecologista y metropolitano, 100\% libre de tarjetas black (en línea) https:/ / arquitecturacontable.wordpress. com/2020/03/31/makers-y-plataformas-de-ensenanza-online-en-la-espana-del-coronavirus-modelos-tecnopoliticos/?fbclid=IwAR2WY1IZ0ZKUiExtaP3-dr9E8H1hQat16t2X6qq8PU-mkXVwP7snSwS1gv4.

Río-Ruiz, Manuel Ángel, Jiménez-Rodrigo, María Luisa y Caro-Cabrera, Manuel Jesús (2015): “The Shifting Financial Aid System in Spanish University: Grant-Recipients'Experiences and Strategies”. Critical Studies in Education, 56 (3), 332-350.

Torrents, Dani (2015): “Trayectorias juveniles y factores de la demanda de educación universitaria española para el año 2009”. Papers. Revista de Sociología, 100 (1), 131-149. DOI: http:/ /dx.doi.org/10.5565/ rev/papers.623. 
Torres, Cristóbal (ed.) (2015). Informe Situación Social de España 2015. Madrid: CIS.

Troiano, Helena y Torrents, Dani (2018): "La evolución del acceso a la universidad en Cataluña: ¿Cómo la explicamos?”. Revista Española de Sociología, 27 (1), 127-136. DOI: http://dx.doi.org/10.22325/fes/ res.2018.8.

\section{Nota biográfica}

Delia Langa-Rosado es profesora titular de la Universidad de Jaén (España). Su principal interés investigador ha girado en torno a las desigualdades educativas. Ha sido respectivamente vicedirectora y directora de la Revista de la Asociación de Sociología de la Educación (2012-2016). Ha realizado diversas estancias de investigación, destacando la del Instituto de Educación de Londres en 2010. Actualmente trabaja en un proyecto I+D sobre inclusividad en la Universidad (Proyecto EDU2017-82862-R).

ORCID: https://orcid.org/0000-0002-7680-828X. 